\title{
KARAKTERISTIK KEWIRAUSAHAAN DAN PERUSAHAAN SERTA KOMPETENSI KEWIRAUSAHAAN SEBAGAI PENENTU KINERJA USAHA KECIL MENENGAH (UKM)
}

\author{
Ernani Hadiyati \\ Fakultas Ekonomi dan Bisnis Universitas Gajayana Malang \\ E-mail:ernani_hadiyati@yahoo.com
}

\begin{abstract}
This project was intended to identify and analyze the simultaneous and partial influence of three observed variables, namely entrepreneurial characteristics, company characteristics, and entrepreneurial competencies, toward business performance. Further, this article explored the aspects contained in entrepreneurial characteristics, company characteristics, and competencies of entrepreneurs and small business performance which eventually resulted in the presentation of data regarding the relationship between the variables studied. The investigation demonstrated two important findings: first, entrepreneurial characteristics, firm characteristics, and entrepreneurial competencies had significant effect on the performance of small businesses simultaneously and partially; second, entrepreneurial competence was recognized as the most influential variables on the small businesses performance.
\end{abstract}

Keywords: Entrepreneurial characteristics, Company characteristics, Entrepreneurial competencies, Business Performance, and Micro, Small, and Medium Enterprises (SMEs)

\begin{abstract}
Abstrak
Tujuan dari penelitian ini adalah mengetahui dan menganalisis pengaruh simultan dan parsial dari variabel karakteristik kewirausahaan, karakteristik perusahaan dan kompetensi wirausaha terhadap kinerja usaha. Artikel ini membahas tentang aspek karakteristik kewirausahaan, karakteristik perusahaan dan kompetensi wirausaha dan kinerja usaha kecil. Hasil akhir penelitian ini menyajikan bentuk hubungan dari variable penelitian. Hasil Penelitian Pertama, karakteristik kewirausahaan, karakteristik perusahaan, dan kompetensi wirausaha berpengaruh signifikan secara simultan terhadap kinerja usaha kecil. Kedua, karakteristik kewirausahaan, karakteristik perusahaan, dan kompetensi wirausaha berpengaruh signifikan secara parsial terhadap kinerja usaha kecil. Ketiga, Kompetensi wirausaha merupakan variabel yang berpengaruh paling besar terhadap kinerja usaha kecil.
\end{abstract}

Kata Kunci: Karakteristik Kewirausahaan, Karakteristik Perusahaan, Kompetensi Kewirausahaan, Kinerja Bisnis dan Usaha Mikro Kecil Menengah(UMKM).

Perguliran era reformasiternyata belum memberikan hasil positif pada kehidupan berbangsa di Indonesia. Fenomena kemiskinan yang terjadi di masyarakat masih menghantuipem- bangunan di Indonesia. Menurut data statistik (BPS, 2012) jumlah penduduk miskin di Indonesia pada Maret 2012 mencapai 29,13 juta orang (11,96 persen), berkurang 0,89 
juta orang (0,53 persen) dibandingkan dengan penduduk miskin pada Maret 2011 yang sebesar 30,02 juta orang (12,49 persen). Selama periode Maret 2011-Maret 2012, penduduk miskin di daerah perkotaan berkurang sekitar 399,5 ribu orang (dari 11,05 juta orang pada Maret 2011 menjadi 10,65 juta orang pada Maret 2012), sementara di daerah perdesaan berkurang 487 ribu orang (dari 18,97 juta orang pada Maret 2011 menjadi 18,48 juta orang pada Maret 2012). Persentase penduduk miskin di daerah perkotaan pada Maret 2011 sebesar 9,23 persen, menurun menjadi 8,78 persen pada Maret 2012. Begitu juga dengan penduduk miskin di daerah pedesaan, yaitu dari 15,72 persen pada Maret 2011 menjadi 15,12 persen pada Maret 2012. Walau secara statistik penduduk miskin di Indonesia mengalami penurunan selama kurun waktu Maret 2011-Maret 2012 kesejahteraan masih belum terwujud secara merata (http://id.wikipedia.org/wiki).

Tujuan Pembangunan Milenium di antaranya yaitu menghapuskan tingkat kemiskinan dan kelaparan, Pemerintah Indonesia telah membuat berbagai kebijakan salah satunya adalah pemberdayaan ekonomi kerakyatan dalamhal ini Usaha Mikro Kecil Menengah(UMKM) dankoperasi. PerananUMKM membantu perekonomian suatu daerah dalam rangka peningkatan pendapatan dan pemerataan pendapatan.

UMKM diharapkan semakin berperan dalam menekan angka pengangguran. Menteri Koperasi dan UKM Syarif Hasan (Depkop, 2012) mengungkapkan, pertumbuhan UMKM di Indonesia meningkat pesat dua tahunterakhir. BiladuatahunlalujumlahUMKM berkisar 52,8 juta unit usaha, pada 2011 sudah bertambah menjadi 55, 2 juta unit. Jumlah UMKM yang terus meningkat ini diharapkan bisa sebanding dengan penyerapan tenaga kerja. Rata-rata UMKM mampu menyerap 3-5 tenaga kerja. Dengan adanya penambahan sekitar 3 juta unit UMKM, dalam dua tahun terakhir, jumlah tenaga yang terserap bertambah 15 juta orang.

Dalam UU No.20/2008 tentang UMKM, didefinisikan bahwa pemberdayaan adalah upaya yang dilakukan Pemerintah, Pemerintah Daerah, Dunia Usaha, dan Masyarakat secara sinergis dalam bentuk penumbuhan iklimdan pengembangan usahaterhadap UMKM sehingga mampu tumbuh dan berkembang menjadi usaha yang tangguh dan mandiri. Prinsip pemberdayaan usaha mikro, kecil, dan menengah adalah: (a) Penumbuhan kemandirian, kebersamaan, dan kewirausahaan usaha mikro, kecil, dan menengah untuk berkarya dengan prakarsa sendiri. (b) Perwujudan kebijakan publik yang transparan, akuntabel, dan berkeadilan. (c) Pengembangan usaha berbasis potensi daerah dan berorientasipasar sesuai dengan kompetensi Usaha Mikro, Kecil, dan Menengah. (d) Peningkatan daya saing usaha mikro, kecil, dan menengah dan kewirausahaan sangat besar peranannya di dalam perkembangan pertumbuhan ekonomi suatu negara.

Penelitian tentang faktor pribadi yang mempengaruhi kinerja bisnis dapat diklasifikasikan menjadi 4 kelompok (Li, 2009), yaitu:(1) Karakteristik pribadi, termasuk dalam kelompok ini adalah penelitian yang berfokus pada sifat dan motif wirausaha yang membedakan dirikerja dengan kewirausahaan. (2) Karakteristik psikologi, menekankan pada pentingnya karakteristik individu, seperti kebutuhan untuk berprestasi, mengambil resiko, kreativitas dan inovasi. (3) Modal manusia, sepertitingkat pendidikan, pengalaman kerja, pengalaman, keterampilan dan pengetahuan teknis. (4) Pendekatan perilaku yang menunjukkan kompetensi identitas dan 
menentukan karakteristik seorang manajer yang sukses. Hal ini didukung oleh pendapat Li (2009) bahwa karakter kepribadian dan kompetensi individu dalam proses kewirausahaan mempengaruhi keberhasilan usaha kecil. Penelitian Chamduang, Daowieng and Jorajit (2012), dalam penelitian yang berjudul: "Pengaruh Karakateristik Kewirausahaan pada keberhasilan Usaha Mikro Kecil Menengah (UMKM) di Songkhla". Hasil penelitiannya menunjukkan bahwa karakteristik kewirausahaan berpengaruh signifikan terhadap keberhasilan usaha kecil.

Penelitian Islam, Khan, Obaidullah dan Alam(2011) dalampenelitian yang berjudul: "Pengaruh Kewirausahaan dan Karakteristik Perusahaan terhadap Keberhasilan Usaha Pada Usaha Kecil Menengah di Bangladesh". Hasil penelitiannya menunjukkan bahwa karakteristik kewirausahaan berpengaruh terhadap keberhasilan pada Usaha Kecil Menengah dan karakteristik perusahaan tidak berpengaruh terhadap keberhasilan usaha pada Usaha Kecil Menengah.

Fokus penelitian pada faktor kompetensi mencoba untuk menguji bagaimana pengaruh kompetensi terhadap kinerja bisnis. Kiggundu (2002) berpendapat bahwa kompetensi kewirausahaan merupakan keseluruhan atribut kewirausahaan yang meliputi sikap, keyakinan, pengetahuan, keterampilan, kemampuan, kepribadian, dan perilaku yang diarahkan untuk mencapai keberhasilan. Lebih lanjut dikemukakan kompetensi kewirausahaan bisa menawarkan pandangan yang tidak realistis tentang bagaimana seseorang mengetahui dalam menjalankan bisnis. Ahmad, N.H., Ramayah, T., Wilson, C., and Kummerow, L. (2010) menemukan bahwa kompetensi kewirausahaan sebagai prediksi keberhasilan usaha UKM di Malaysia, bahkan pengaruhnya kuat terhadap kondisi lingku- ngan yang stabildan dinamis. Rumusan masalah dalam penelitian adalah bagaimanakah karakteristik kewirausahaan, karakteristik perusahaan dan kompetensi wirausaha berpengaruh simultan dan parsial terhadap kinerja usaha kecil? Tujuan penelitian adalah untuk mengetahui dan menganalisis karakteristik kewirausahaan, karakteristik perusahaan dan kompetensi wirausaha berpengaruh simultan dan parsial terhadap kinerja usaha kecil.

\section{Metode Penelitian}

Lokasi penelitian di Kota Malang pada Usaha kecil sentra produk kerajinan di kota Malang. Jenis penelitian adalah explanatory research.

Sumber data menggunakan data primer dan sekunder. Data Primer diperoleh dari jawaban responden sehubungan dengan variable karakteristik perusahaan, karakteristik kewirausahaan, kompetensi kewirusahaan. Data sekunder diperoleh dari kantor disperindag kota Malang meliputi gambaran umum usaha kecil menengah, data skala usaha sentra usaha kecil sektor kerajinan.

Populasi penelitian adalah para pemilik usaha kecil sentra produk kerajinan di Kota Malang. Sampel penelitian ditentukan dengan pendekatan Rumus Slovin dan jumlahnya 375 pengusaha unit usaha kecil.

Metode pengumpulan data dengan penyebaran kuesioner kepada responden. Untuk uji instrument penelitian dengan menggunakan validitas dan reliabilitas.

Pengukuran varibel penelitian menggunakan skala likert dengan skala lima tingkatan dari tingkatan yang paling tinggisangat setuju (SS) sampaidengan tingkatan paling rendah sangat tidak setuju (STS).

Metode analisa data dengan menggunakan analisa uji diskriptif dengan statistik diskriptif dan uji infrensial menggunakan uji 
hipotesa dengan regresi berganda. Analisa data dengan menggunakan program SPSS.

\section{Hasil Penelitian dan Pembahasan}

Deskripsi responden berdasarkan tingkat usia, dari usia 21-30 tahun sebanyak 19 responden atau sebesar 5,06\%, usia 31-40 tahun sebanyak 97 responden atau sebesar 25,86\%, usia 41-50 tahun sebanyak 124 responden atau sebesar 33,06\%, usia 51-60 tahun sebanyak 102 responden atau sebesar 27,2 \%, dan usia 61-70 tahun sebanyak 33 responden atau sebesar $8,8 \%$. Hal ini menunjukkan bahwa responden atau pengusaha paling banyak berusia antara 41-50 tahun.

Deskripsi responden berdasarkan tempat tinggal, di Kecamatan Blimbing sebanyak 22 responden atau sebesar $5,6 \%$, di Kecamatan Kedungkandang sebanyak 94 responden atau sebesar 25,06\%, di Kecamatan Klojen sebanyak 55 responden atau sebesar 14,66\%, di kecamatan Lowokwaru sebanyak 98 responden atau sebesar $26,13 \%$ dan di kecamatan Sukun sebanyak 102 responden atau sebesar 27,2\%. Hal ini menunjukkan bahwa letak sentra Usaha Kecil Me- nengah (UKM) yang paling banyak di wilayah Kecamatan Sukun.

Tingkat pendidikan responden meliputi: tingkat SMA sebanyak 194 responden atau sebesar 51,73\%, tingkat S1 sebanyak 172 responden atau sebesar $45,86 \%$, tingkat $\mathrm{S} 2$ sebanyak 7 responden atau sebesar 1,86\%, tinggkat $\mathrm{S} 3$ sebanyak 2 responden atau sebesar $0,53 \%$. Hal ini menunjukkan bahwa tingkat pendidikan terakhir pemilik usaha paling banyak pada tingkat pendidikan SMA.

Dalam menguji hipotesis dengan analisis regresi berganda untuk mengetahui besarnya pengaruh dari variabel Karakteristik Kewirausahaan $\left(\mathrm{X}_{1}\right)$, Karakteristik perusahaan $\left(\mathrm{X}_{2}\right)$, Kompetensi wirausaha $\left(\mathrm{X}_{3}\right)$ terhadap Kinerja usaha (Y). Untuk lebih jelasnya dapat dilihat pada tabel 1 .

Hasil perhitungan regresi berganda dapat disusun formulasinya sebagai berikut:

$$
\begin{aligned}
& Y=a+b_{1} X_{1}+b_{2} X_{2}+b_{3} X_{3}+e \\
& Y=8,683+3,680 X_{1}+4,745 X_{2}+21,869 \\
& X_{3}+e
\end{aligned}
$$

Berdasarkan hasil persamaan terse-

\begin{tabular}{|c|c|c|c|c|}
\hline Variabel & Keterangan & $\begin{array}{c}\text { Koefisien } \\
\text { Regresi }\end{array}$ & $t_{\text {hitung }}$ & Sig. \\
\hline $\mathrm{X} 1$ & Karakteristik Kewirausahaan & 0,156 & 0,112 & 0,000 \\
\hline $\mathrm{X} 2$ & Karakteristik perusahaan & 0,265 & 0,151 & 0,000 \\
\hline $\mathrm{X} 3$ & Kompetensi Wirausaha & 0,720 & 0,718 & 0,000 \\
\hline Konstanta & 8,663 & & & \\
\hline $\mathrm{R}$ & 0,826 & & & \\
\hline R Square & 0,683 & & & \\
\hline$F_{\text {hitung }}$ & 265,846 & & & \\
\hline Sig. F & 0,000 & & & \\
\hline n & 375 & & & \\
\hline \multicolumn{5}{|c|}{ Variabel terikat $=$ Kinerja Usaha $(\mathrm{Y})$} \\
\hline
\end{tabular}
but, maka dapat dijelaskan sebagai berikut:

Tabel 1. Hasil Analisa Regresi Berganda 
(a) Konstanta (a) $=8,683$ menunjukkan besarnya kinerja, jika Karakteristik Kewirausahaan $\left(\mathrm{X}_{1}\right)$, Karakteristik perusahaan $\left(\mathrm{X}_{2}\right)$, Kompetensi Wirausaha $\left(\mathrm{X}_{3}\right)$ masing-masing $=0$, maka besaran kinerja usaha kecil akan sebesar 8,683. Koefisien regresi $X_{1}$ (Kewirausahaan) sebesar 0,156 dan hasilnya positif, hal ini menunjukkan bahwa jika karakteristik kewirausahaan meningkat maka kinerja usahakecil(Y) cenderung meningkat. Hal inibisa diartikan bahwa karakteristik kewirausahaan mampu meningkatkan kinerja usaha. Jika variabel karakteristik kewirausahaan tidak berperan maka kinerja usaha akan menurun. (b) Koefisien regresi $\mathrm{X}_{2}$ (Karakteristik perusahaan) sebesar 0,265 dan hasilnya positif, hal ini menunjukkan bahwa karakteristik perusahaan memiliki peran yang positif terhadap kinerja usaha kecil(Y). Hal ini bisa diartikan bahwa variabel karakteristik perusahaan ada kecenderungan meningkatkan kinerja usaha. (c) Koefisien regresi $\mathrm{X}_{3}$ (Kompetensi Wirausaha) sebesar 0,720 dan hasilnya positif, halini menunjukkan bahwa Kompetensi dari Wirausaha mampu meningkatkan kinerja usaha kecil (Y). Hal ini bisa diartikan bahwa variabel Kompetensi Wirausaha berperan dalam meningkat kinerja usaha.

Dari hasil perhitungan nilai $\mathrm{F}_{\text {hitung }}$ sebesar 265,846, dengan nilai signifikansi sebe- sar 0,000 lebih kecil dari a =0,05 (0,000 < 0,05), maka variabelbebas: Karakteristik kewirausahaan $\left(\mathrm{X}_{1}\right)$, Karakteristik perusahaan $\left(\mathrm{X}_{2}\right)$, Kompetensi wirausaha $\left(\mathrm{X}_{3}\right)$ secara simultan atau bersama-sama berpengaruh signifikan terhadap variabelY (kinerja usaha kecil). Untuk menguji hipotesa kedua berdasarkan hasil perhitungan $t_{\text {hitung }}$ masing-masing variabel bebas tercantum di tabel 2 .

Pertama, Variabel $\mathrm{X}_{1}$ (Karakteristik kewirausahaan) Hasil analisis regresi diperoleh nilai $t_{\text {hitung }}=3,680$ sehingga dengan nilai signifikansi $0,000<0,05$, sehingga terbukti bahwa variabel $\mathrm{X}_{1}$ (Karakteristik kewirausahaan) berpengaruh signifikan terhadap Kinerja usaha (Y).

Kedua, Variabel $\mathrm{X}_{2}$ (Karakteristik perusahaan) Hasil analisis regresi diperoleh nilai $\mathrm{t}_{\text {hitung }}=4,745$ dengan nilai signifikansi 0,007 $<0,05$, sehingga terbukti bahwa variabel $\mathrm{X}_{2}$ (Karakteristik perusahaan) berpengaruh signifikan terhadap Kinerja usaha (Y).

Ketiga, Variabel $\mathrm{X}_{3}$ (Kompetensi Wirausaha) Hasil analisis regresi diperoleh nilai $\mathrm{t}_{\text {hitung }}=21,869$ dengan nilai signifikansi 0,000 $<0,05$, sehingga terbukti bahwa variabel $\mathrm{X}_{3}$ (Karakteristik perusahaan) berpengaruh signifikan terhadap Kinerja usaha (Y).

Untuk membuktikan kompetensi wirausaha yang paling dominan terhadap kinerja, maka peneliti melihat dari besarnya koefisien

Tabel 2. Perbandingan $t_{\text {hitung }}$ dan $t_{\text {tabel }} \alpha=5 \%$

\begin{tabular}{cccc}
\hline Variabel & thitung & Sig & Keterangan \\
\hline$X_{1}$ & 3,680 & 0,000 & Signifikan \\
$X_{2}$ & 4,745 & 0,000 & Signifikan \\
$X_{3}$ & 21,869 & 0,000 & Signifikan
\end{tabular}

Sumber: Data diolah, tahun 2013 
Ekonomika-Bisnis Vol. 5 No.2 Bulan Juli Tahun 2014. Hal 117-124

regresi masing-masing variable. Sesuai pada tabel 1 angka koefisien regresi yang paling besar berpengaruh dibandingkan karakteristik kewirausahaan $\left(\mathrm{X}_{2}\right)$ dan karakteristik perusahaan adalah variable kompetensi kewirausahaan $\left(\mathrm{X}_{3}\right)$ yaitu sebesar 0,720 .

\section{Penutup}

Berdasarkan hasil penelitian ini, maka dapat diambil kesimpulan bahwa: (1) Karakteristik kewirausahaan, Karakateristik perusahaan dan Kompetensi Kewirausahaan berpengaruh simultan dan signifikan terhadap kinerja usaha. (2) Karakteristik kewirausahaan, Karakateristik perusahaan dan Kompetensi Kewirausahaan berpengaruh parsial dan signifikan terhadapkinerja usaha. (3) Kompetensi wirausaha berpengaruh paling besar terhadap kinerja usaha.

Berdasarkan kesimpulan di atas, maka rekomendasinya sebagai berikut: (1) Pemerintah dalam memberikan program pengembangan UMKM perlu mempertimbangkan karakteristik kewirausahaan, karakteristik perusahaan dan Kompetensi Kewirausahaan, hal ini menentukan kinerja usahanya. (2) Pengusaha harus memiliki kesadaran bahwa untuk mencapai kinerja yang baik perlu mengikutiprogrampengembangan UMKMyang dilakukan pemerintah yang mampu mengubah karakteristik dan kompetensi wirausaha yang lebih baik.

\section{DAFTAR PUSTAKA}

Ahmad, N.H., Ramayah, T., Wilson, C., dan Kummerow, L. 2010. Is Entrepreneurial Competency and Business Success Relationship Contingent Upon Business Environment? A Studi of Malaysian SMEs. International Journal of Entrepreneurial Behaviour \& Research, 16(3), 182-203.
Arikunto, S. 2006. Prosedur Penelitian Suatu Pendekatan Praktek. Penerbit Cipta. Jakarta.

Bandura, A. 1977. Social Learning Theory. Englewood Cliffs. Prentice-Hall. New Jersey.

Beal, R.M. 2000. Competing Effectifely: Environmental Scanning Competitive Strategy And Organizational Performance: The Small Manufacturing Firms, Journal of Small Business Management, 22, 27-45.

Birley, S., \& Westhead P. 1994. ATaxonomy of Business Start-Up Reasons and Their Impact on Firm Growthand Size. Journal of Business Venturing, Vol. 9, No. 1: 7-31.

Boyatzis, R.E. 1982. The Competent Manager: A Model for Effective Performance. Wiley. New York.

Chamduang, Daowieng, Jorajit. 2012. Effect of Entrepreneurial Characteristics on the Business Success of Small and MediumEnterprises in Songkhla. Proceedings-Sufficiency Economy and Community Enterprise-001 $4^{\text {th }}$ International Conference on Humanities and Social Sciences April 21st, Faculty of Liberal Arts, Prince of Songkla University, pp. 176-19.

Covin, J. G., \& Slevin, D. P. 1991. A Conceptual Model of Entrepreneurship as Firm Behaviour. Entrepreneurship Theory and Practice, Vol. 16, No. 1: $7-25$.

Cragg, P. B., \& King, M. 1988. Organizational Characteristics and Small Firms' Performance Revisited. Entrepreneurship Theory and Practice, Vol. 13, No. 2: 49-64. 
Karakteristik Kewirausahaan dan Perusahaan.... (Ernani Hadiyati)

Cromie, S. 2000. Assessing entrepreneurial inclinations: Some approaches and empirical evidence. European Journal of Work and Organizational Psychology, 9(1), 7-20.

Duchesneau, D., \& W. Gartner. 1990. Aprofile of new venture success and failure in an emerging industry. Journal of Business Venturing, 5 (5), 297-312.

Endi, S., Surachman, Armanu, dan Hadiwidjojo Djumilah, (2013), Entrepreneurial characteristic and Competencyas Determinants Of Business Performance in SMEs, Jurnal of Business Management, University of Brawijaya, Malang, Volume 7, Issue 3 (January - February).

Glancey, K., Greig, M., \& Pettigrew, M. 1998. Entrepreneurial Dynamics in Small Business Service Firms.International Journal of Entrepreneurial Behaviour \& Research, Vol. 4, No. 3: 249-268.

Harvie, Narjoko dan Oum. 2010. Firm Cracteristic Determinants Of SME Participation in Production Networks. ERIA Discussion Paper Series. Gelora Bung Karno. Jakarta Pusat.

Islam, Khan dan Obaidullah. 2011. Effect of Entrepreneur and Firm Characteristics on the Business Success of Small and Medium Enterprises (SMEs) in Bangladesh .International Journal of Business and Management Vol. 6, No. 3;pp 97-115, March.

Jauch, L.R. and Glueck, W.F. 1998. Business Policy and Strategic Management. Mc-Graw-Hill Books Company. Singapore.

Kiggundu, M.N. 2002. Entrepreneurs and
Entrepreneurship in Africa: what is known and what needs to be done, Journal of Development Entrepreneurship, 7(3), 239-258.

Kolvereid, L. 1996. Prediction of Employment Status Choice Intentions. Entrepreneurship Theory and Practice, Fall, 47-57

Lee D.Y. and Tsang, E.W.K. 2001. The Effect of Entrepreneurial Personality, Background and Network Activities on Venture Growth. Journal of Management Studies, 38(4), 583-602.

Li, H., Zhang, Y. and Chan, T.SN. 2005. Entrepreneurial Strategy Making and Performance in China's New Technology Ventures - The Contingency Effect of Environment and Firm Competence, Strategic Management Journal, 16, 2005, 37-57.

Lumpkin, G. T., \& Dess, G. G. 1996. Clarifying the Entrepreneurial Orientation Construct and Linking It to Performance. Academy of Management Review, Vol. 21, No. 1: 135-172.

Lumpkin, G T., \& Dess, G. G. 2001. Linking Two Dimensions of Entrepreneurial Orientation to Firm.Performance: The Moderating Role of Environment and Industry Life Cycle. Journal of Business Venturing, Vol.16, No. 5: 429_ 451.

Man, T.W.Y. and Lau T. 2005. The Contect of Entrepreneurship in Hongkong: an investigation through the patterns of entrepreneurial competencies in contrasting industrial environments, Journal of Small Business and Enterprise Development, 12(4), 67-92.

McMahon, R. G. P. 2001. Growth and per- 
Ekonomika-Bisnis Vol. 5 No.2 Bulan Juli Tahun 2014. Hal 117-124

formance ofmanufacturing SMEs: The influence of financial management characteristics. International Small Business Journal, 19(3), 10-28.

Nooteboom, B. 1994. Innovation and Diffusion in Small Firms: Theory and Evidence. Small Business Economics, Vol. 6, No. 5: 327 - 347.

Sanchez, A.A. and Marin, G.S. 2005. Orientation Management, Characteristic, and Performance. AStudy Spanish SME's. Journal of Small Business Management, 43 (3), 287-306.

Smallbone, D., Leig, R., \& North, D. 1995. The characteristics and strategies of high growth SMEs. International Journal of Entrepreneurial Behaviour and Research, 1(3), 44.

Stewart Jr., W. H., Watson, W. E., Carland, J. C., \& Carland, J. W. 1998. A Proclivity for Entrepreneurship: AComparison of Entrepreneurs, Small Business Owners, and Corporate Managers. Journal of Business Venturing, Vol. 14, No. 2: 189 - 214.

Street, C.T and Cameron, A.F. 2007. External Relationships and the Small Business: AReview of Small Business Alliance and Network Research, Journal of Small Business Management, $45(2)$.

Undang - Undang, Republik Indonesia Nomor 20 Tahun 2008 tentang Usaha Mikro Kecil Menengah.

Westhead, P. 1995. Survival And Employment Growth Contrasts Between Types OfOwner-Managed High Technology Firms. Entrepreneurship Theory \& Practice, 20 (1), 5- 28.
Wijewardena, H., \& S. Cooray. 1996. Factors contributing to the growth of small manufacturing firms: perceptions on Japanese owner/managers. Journal of Enterprising Culture, 4(4), 351-361.

Yusuf, A. 1995. Critical Success Factors For Small Business: Perceptions Of South Pacific Entrepreneurs. Journal Of Small Business Management, 33 (2), 68-73.

Zoysa, A. De \& Herath, S.K. 2007. The impact of owner/managers' mentality on financial performance of SMEs in Japan: An empirical investigation. Journal of Management Development, 26(7), 2007, 652-666. 